\title{
A Mixed Integer Programming Model to Evaluate the Impact of Business Factors on Global Manufacturing Relocation Decisions
}

\author{
Abraham Zhang ${ }^{1}$, George Q. Huang \\ ${ }^{1}$ Department of Industrial and Manufacturing Systems Engineering, \\ The University of Hong Kong, Hong Kong. (abraham.zhang@hkusua.hku.hk)
}

\begin{abstract}
In recent years, dramatic changes in business factors have triggered a trend of manufacturing relocation out of "The World's Factory", which is the Pearl River Delta (PRD), China. Global manufacturers in PRD have been facing unprecedented operating cost pressure, due to RMB currency appreciation, rising labor cost, highly volatile oil price, tax rebate adjustment and industry policy changes. This paper presents a Mixed Integer Programming (MIP) model, to evaluate the impact of business factors on global manufacturing relocation decisions. Objective function of the MIP model is to minimize Total Landed Cost (TLC) for international markets. Application of the MIP model is illustrated through a case study with a hypothetical footwear manufacturer. Managerial implications on supply chain dynamics and regional economy are derived from modeling results and analysis.
\end{abstract}

Keywords: Global Manufacturing, Supply Chain, Relocation Decision, Mixed Integer Programming, Pearl River Delta

\section{INTRODUCTION}

During the 1990s, The Pearl River Delta (PRD) of China had gained the fame as "The World's Factory", as it hosted many global manufacturers. However, in recent few years, dramatic changes in business factors have brought unprecedented cost pressure for global manufacturers in PRD. From 2005 to 2008, RMB¥ to US $\$$ exchange rate had risen by about $20 \%$. Minimum wage standards among cities in PRD had increased by about $70 \%$ from 2004 to 2008 . During the same period, international crude oil prices had hit historical high levels. Transportation costs and prices for many industrial raw materials, like plastics and metals, also fluctuated wildly, as they have strong correlation with oil price. In 2007, China's central government reduced export Value-added Tax (VAT) rebates significantly for a very large category of labor and energy intensive products. Local governments in PRD also stopped offering land incentives and corporate tax incentives to these industries. As a result, a large number of manufacturers have ceased their operations in PRD since 2007. Many manufacturers have relocated, or in plan to relocate out of PRD. The trend of global manufacturing relocation is expected to have significant impact on the global supply chain dynamics and the economy of certain regions.

Despite the significance of the phenomenon, little scholarly research can be found among English literature. This paper aims to narrow the gap by answering the following research questions:

(1) How to model the impact of business factors on global manufacturing relocation decisions?

(2) How would changes in business factors impact relocation decisions?
(3) What are the managerial implications?

The research adopts mathematical modeling approach by using Mixed Integer Programming (MIP) techniques, which has been used most widely in Supply Chain Management (SCM) areas (Arisoy, 2007). Managerial implications are derived from modeling results.

The paper is organized as follows. Section 2 reviews relevant literature on global manufacturing and mathematical models. Section 3 introduces a MIP model. Section 4 presents the experimental design. Section 5 gives modeling results. Section 6 discusses managerial implications. Section 7 concludes the research.

\section{LITERATURE REVIEW}

\subsection{Global Manufacturing}

The past three decades have witnessed the advancement of global manufacturing. Reductions of worldwide trade barriers, global standardization of products and technology innovation have contributed to the trend (Ferdows, 1989). Advantages of global manufacturing include tangible benefits like tariff and trade concession, lower labor cost, lower logistics cost in foreign markets. Intangible benefits include responsiveness to customer needs, learning opportunities from suppliers and attraction of global talent (Ferdows, 1997).

Decisions in the global manufacturing activities can be distinguished into two types: 'configuration' and 'coordination'. Configuration concerns mainly on structural requirements of setting up a global network of operations and allocating resources along the product value-chain. Coordination is related with management

978-1-4244-4136-5/09/\$25.00 @2009 IEEE 
of such a network to achieve the firm's strategic objectives (Fawcett, Birou, \& Taylor, 1993; Pontrandolfo \& Okogbaa, 1999). The research proposed is a 'configuration' issue.

\subsection{Mathematical Models}

Several papers reviewed mathematical models relevant to global manufacturing location decisions (Vidal \& Goetschalckx, 1997; Beamon, 1998; Min \& Zhou, 2002; Bilgen \& Ozkarahan, 2004; Meixell \& Gargeya, 2005). In general, mathematical models helped increase profitability and reduce risks from uncertainties.

Most models were to aid location decisions under given business conditions. Only few studies addressed explicitly how happened or potential changes in business factors impact global manufacturing location decisions (Huchzermeier \& Cohen, 1996; Vidal \& Goetschalckx, 2000; Mohamed \& Youssef, 2004). Though exchange rate risk was addressed by these studies, little research has been done on the impact of changes in labor cost, oil price and tax incentives, which may be more influential on global manufacturing trends. In addition, none of these models were based on similar business context as the research proposed.

\section{A MIP MODEL}

The research builds a MIP model to evaluate the impact of business factors on global manufacturing relocation decisions. As PRD is dominant with low-cost global manufacturing activities, the research assumes that cost is the market winning factor. The MIP model assumes that certain demand of one product in international markets is to be met by one manufacturing facility. Transportation costs, raw material prices and utility cost are assumed to be in liner correlation with oil price. Their short term fluctuations caused by other factors are not considered. Objective function of the model is to minimize Total Landed Cost (TLC) in international markets. The model is formulated by using the variables and parameters as defined in table 1,2 and 3. After presentation of the model formulation, model components are described and discussed.

Table 1: Decision variables

\begin{tabular}{|l|l|}
\hline $\begin{array}{l}\text { Decision } \\
\text { variables }\end{array}$ & Description of decision variables \\
\hline Openfacility $_{f}$ & $\begin{array}{l}\text { Binary value associated with facility } \\
f(1 \text { if open; } 0 \text { if not open })\end{array}$ \\
\hline$q_{f m}$ & $\begin{array}{l}\text { Yearly manufacturing quantity at } \\
\text { facility } \mathrm{f} \text { for market } \mathrm{m}\end{array}$ \\
\hline$S P_{f}$ & Unit selling price from facility $\mathrm{f}$ \\
\hline
\end{tabular}

Table 2: Parameters

\begin{tabular}{|l|l|}
\hline Parameters & Description of parameters \\
\hline
\end{tabular}

\begin{tabular}{|c|c|}
\hline$M$ & Markets $\{1,2, \ldots \mathrm{m}, \ldots \mathrm{M}\}$ \\
\hline$F$ & Facilities $\{1,2, \ldots \mathrm{f}, \ldots \mathrm{F}\}$ \\
\hline$I$ & $\begin{array}{l}\text { Imported raw materials }\{1,2, \ldots \mathrm{i}, \\
\ldots \mathrm{I}\}\end{array}$ \\
\hline$L$ & $\begin{array}{l}\text { Local raw materials }\{1,2, \ldots 1, \ldots \\
\text { L\} }\end{array}$ \\
\hline$D_{m}$ & Yearly demand for market $m$ \\
\hline OTC_base $e_{f}$ & $\begin{array}{l}\text { Base unit cost for outbound } \\
\text { transportation from facility } f\end{array}$ \\
\hline$S C_{-} b a s e_{f m}$ & $\begin{array}{l}\text { Base unit cost for port to port } \\
\text { shipping from facility } f \text { to market } m\end{array}$ \\
\hline$M T C \_b a s e_{m}$ & $\begin{array}{l}\text { Base unit cost for transportation in } \\
\text { market } m\end{array}$ \\
\hline$I R M P \_$base $_{i f}$ & $\begin{array}{l}\text { Base price of imported raw material } \\
i \text { sold to facility } f\end{array}$ \\
\hline$L R M P \_P_{\text {base }} e_{l f}$ & $\begin{array}{l}\text { Base price of local raw material } l \\
\text { sold to facility } f\end{array}$ \\
\hline$R L C_{f}$ & Relocation cost of opening facility $f$ \\
\hline$\overline{D e p_{f}}$ & Yearly depreciation ratio of $R L C_{f}$ \\
\hline$C R C_{f}$ & $\begin{array}{l}\text { Unit capacity retaining cost at } \\
\text { facility } f\end{array}$ \\
\hline$U_{-}$base $_{f}$ & Base unit utility cost at facility $f$ \\
\hline$D L_{-}$rate $_{f}$ & Hourly direct labor rate at facility $f$ \\
\hline$D L \_h r_{f}$ & $\begin{array}{l}\text { Man hour per unit of production at } \\
\text { facility } f\end{array}$ \\
\hline$O P$ & Crude oil price \\
\hline$O P B$ & Crude oil base price \\
\hline $\operatorname{Exch}_{f}$ & $\begin{array}{l}\text { Exchange rate to US } \$ \text { from the } \\
\text { currency used for facility } f\end{array}$ \\
\hline$C \operatorname{Tax}_{f}$ & Corporate tax rate for facility $f$ \\
\hline$V A T_{f}$ & $\begin{array}{l}\text { Actual VAT rate for facility } f \text { with } \\
\text { consideration of VAT rebate }\end{array}$ \\
\hline$N P A T_{f}$ & Net profit after tax rate for facility $f$ \\
\hline $\mathrm{DOI}_{f}$ & Days of inventory at facility $f$ \\
\hline Tariff $_{f m}$ & $\begin{array}{l}\text { Tariff rate imposed by market } m \text { for } \\
\text { the product imported from facility } f\end{array}$ \\
\hline$R M P \_O i l$ & $\begin{array}{l}\text { Correlation factor between raw } \\
\text { material prices and oil price }\end{array}$ \\
\hline U_Oil & $\begin{array}{l}\text { Correlation factor between utility } \\
\text { costs and oil price }\end{array}$ \\
\hline OTC_Oil & $\begin{array}{l}\text { Correlation factor between } \\
\text { outbound transportation costs and } \\
\text { oil price }\end{array}$ \\
\hline SC_Oil & $\begin{array}{l}\text { Correlation factor between shipping } \\
\text { costs and oil price }\end{array}$ \\
\hline$M$ & $\begin{array}{l}\text { Correlation factor between market } \\
\text { transportation costs and oil price }\end{array}$ \\
\hline$C O E F_{-} I n v$ & $\begin{array}{l}\text { Yearly inventory holding cost as a } \\
\text { percentage of total inventory value }\end{array}$ \\
\hline$L$ & A sufficiently large constant \\
\hline
\end{tabular}

Table 3: Convenience variables \begin{tabular}{|l|l|}
\hline Convenience & Description of convenience variables \\
\hline
\end{tabular} 


\begin{tabular}{|l|l|}
\hline Variables & \\
\hline$S t d_{-} \cos t_{f}$ & $\begin{array}{l}\text { Standard cost of the product at } \\
\text { facility } f\end{array}$ \\
\hline$O T C_{f}$ & $\begin{array}{l}\text { Unit outbound transportation cost for } \\
\text { the product departing from facility } f\end{array}$ \\
\hline$S C_{f m}$ & $\begin{array}{l}\text { Port to port unit shipping cost from } \\
\text { facility } f \text { to market } m\end{array}$ \\
\hline$M T C_{f}$ & $\begin{array}{l}\text { Unit market transportation cost for } \\
\text { the product in market } m\end{array}$ \\
\hline$R M C_{f}$ & $\begin{array}{l}\text { Raw material cost for each unit of the } \\
\text { product at facility } f\end{array}$ \\
\hline$C T A X C_{f}$ & Corporate tax per unit at facility $f$ \\
\hline$V A T C_{f}$ & VAT per unit at facility $f$ \\
\hline$I n v_{-} \cos t_{f}$ & Inventory cost per unit at facility $f$ \\
\hline$L C_{f m}$ & $\begin{array}{l}\text { Landed cost per unit from facility } f \text { to } \\
\text { market } m\end{array}$ \\
\hline
\end{tabular}

Objective Function:

Minimize

$$
\begin{aligned}
& \sum_{f} \sum_{m} S P_{f} q_{f m}+\sum_{f} \sum_{m}\left(O T C_{f} q_{f m}+S C_{f m} q_{f m}+M T C_{m} q_{f m}\right) \\
& +\sum_{f} \sum_{m} \operatorname{Tariff}_{f m} S P_{f m} q_{f m}
\end{aligned}
$$

Subject to:

$$
\begin{aligned}
& U_{f}=U_{-} \text {base }_{f} \operatorname{Exch}_{f}\left(1+U_{-} \text {Oil }(O P / O P B-1)\right) \\
& \forall f \in F \\
& R M C_{f}=\left(\sum_{i} I R M P_{-} b a s e_{i f}+\sum_{l} L R M P_{-} \text {base }_{l f} E x c h_{f}\right) \\
& \times\left(1+R M P \_O i l(O P / O P B-1)\right) \\
& \forall f \in F \\
& I n v_{-} \cos t_{f}=R M C_{f} D O I_{f} C O E F_{-} I n v / 365 \\
& \forall f \in F \\
& S t d_{-} \cos t_{f}=E x c h_{f}\left(\begin{array}{l}
R L C_{f} \operatorname{Dep}_{f} \operatorname{Exch}_{f} / \sum_{m} D_{m} \\
+C R C_{f}+D L_{-} \text {rate }_{f} D L_{-} h r_{f}
\end{array}\right) \\
& +U_{f}+R M C_{f}+I n v_{-} \cos t_{f} \\
& \forall f \in F \\
& O T C_{f}=O T C_{-} \text {base }_{f} \mathrm{Exch}_{f} \\
& \times\left(1+O T C \_O i l(O P / O P B-1)\right) \\
& \forall f \in F(6) \\
& S C_{f}=S C_{-} \text {base }_{f}\left(1+S C_{-} \text {Oil }(O P / O P B-1)\right) \\
& \forall f \in F(7) \\
& M T C_{f}=M T C_{-} \text {base }_{f}\left(1+M T C_{-} \text {Oil }(O P / O P B-1)\right) \\
& \forall f \in F \\
& C T A X C_{f}=\operatorname{Ctax}_{f}\left(S P_{f}-S t d_{-} \cos t_{f}-V A T C_{f}\right) \\
& \forall f \in F \\
& V A T C_{f}=V A T_{f}\left(S P_{f}-R M C_{f}\right) \\
& \forall f \in F(10) \\
& S P_{f}-S t d_{-} \cos t_{f}-V A T C_{f}-C T A X C_{f}=N P A T_{f} S P_{f} \\
& \forall f \in F \\
& L C_{f m}=S P_{f}+O T C_{f}+S C_{f}+M T C_{f}+\operatorname{Tariff}_{f m} S P_{f} \\
& \forall f \in F \quad \& \quad m \in M
\end{aligned}
$$

$$
\begin{array}{lr}
\sum_{f} q_{f m}=D_{m} & \forall m \in M \\
\sum_{m} q_{f m} \leq \text { LOpenfacility } & \\
\sum_{f} \text { Openfacility }=1 & \forall f \in F \\
q_{f_{m}} \text { is integer, }_{\text {Openfacility }_{f} \in\{0,1\}} & \forall f \in F \quad \& m \in M \\
\text { Alf }_{\text {f }} & \forall f \in F
\end{array}
$$

All variables $\geq 0$

The objective function (1) minimizes TLC in all international markets. TLC components include buyers' purchasing costs at EXW term, transportation costs and tariff costs. Equations (2) to (8) are convenience constraints to simplify model formulations while defining individual cost components, including utility cost, raw material cost, inventory cost, standard cost, outbound transportation cost, shipping cost and market transportation cost. Standard cost is the total manufacturing cost per unit, including all variable manufacturing cost and facility cost. Equations (9) to (11) defines selling price in relation to standard cost, corporate tax and VAT. Equation (12) is a convenience constraint on Landed Cost (LC) per unit, in order to export the result data for analysis. Equation (13) is a demand constraint. Equation (14) is a binary force constraint. Equation (15) defines that only one facility can be opened. Equations (16) to (18) define the characteristics of variables.

\section{EXPERIMENTAL DESIGN}

We apply the MIP model to a hypothetical footwear global manufacturer operating in PRD. The footwear manufacturer produce low-end to middle-end sports shoes with a retail price of about US\$20 in international markets. As an illustration, the case study considers a stable demand in US market. Shortlisted relocation destinations include three alternative locations in China. They are a location outside of PRD but Close to PRD (C-PRD), a city within Pan-PRD region, and an Inland city in China. Two nearby overseas low cost locations are shortlisted, and they are Hanoi in Vietnam and Chennai in India. Jimenez, which is a Mexico city near to US border, is also considered due to its proximity to market.

\subsection{Data Sources}

Most cost related data for the case study was obtained from official web sites of governmental agencies and industrial associations. They include Hong Kong Trade Development Council, State Administration of Foreign Exchange (China), Ministry of Finance (China), Guangdong Municipal Labor \& Social Security Bureau, United States Department of Labor, Asia Footwear Association and Shenzhen Container Trailer Association. Shipping rates are based on quotations from two shipping lines and two freight forwarders. 


\subsection{Design of Experimental Scenarios}

An experimental scenario is defined as a unique combination of parameter values, which represent business factors. The base scenario represents the best prediction on the future business environment for the planning horizon of 10 years. Table 4 shows parameter values at the base scenario. RMB $¥$ to US\$ exchange rate is 0.14 . Labor costs in all candidate locations are set as in 2007. Export VAT rebate in China is set at $13 \%$. Average crude oil price is projected to be at US\$75 per barrel. Table 5 shows a set of scenarios for sensitivity analysis, to assess the impact of business factors on LC.

Table 4: Base scenario

\begin{tabular}{|l|l|}
\hline Parameter & Parameter value \\
\hline RMB¥ to US\$ exchange rate & 0.14 \\
\hline Export VAT rebate in China & $13 \%$ \\
\hline DL Labor costs & As in 2007 \\
\hline Crude oil price (US\$/barrel) & 75 \\
\hline
\end{tabular}

Table 5: Scenarios for sensitivity analysis

\begin{tabular}{|l|l|}
\hline $\begin{array}{l}\text { Business factor for } \\
\text { sensitivity analysis }\end{array}$ & Parameter value \\
\hline $\begin{array}{l}\text { RMB¥ to US\$ exchange rate in } \\
\text { comparison with base scenario }\end{array}$ & $\begin{array}{l}110 \% ; 120 \% ; 130 \% ; \\
140 \%\end{array}$ \\
\hline $\begin{array}{l}\text { Labor cost at all locations in } \\
\text { comparison with base scenario }\end{array}$ & $\begin{array}{l}125 \% ; 150 \% ; 175 \% ; \\
200 \%\end{array}$ \\
\hline Crude oil price (US\$/barrel) & $37.5 ; 150 ; 225 ; 300$ \\
\hline Export VAT rebate in China & $0 \% ; 4 \% ; 8 \% ; 17 \%$ \\
\hline
\end{tabular}

\section{RESULTS AND ANALYSIS}

The MIP model is resolved with commercial software ILOG OPL 6.1.1. CPU running time for all scenarios is less than 5 seconds on a computer with Intel ${ }^{\circledR}$ Dual-core $1.5 \mathrm{G}$ processor and $2 \mathrm{G}$ RAM.

\subsection{Base Scenario Analysis}

Table 6: Landed cost comparison at base scenario

\begin{tabular}{|l|c|c|}
\hline & $\begin{array}{c}\text { Landed cost } \\
\text { per unit }\end{array}$ & Difference to PRD \\
\hline PRD & $\$ 5.77$ & - \\
\hline C-PRD & $\$ 4.97$ & $-13.8 \%$ \\
\hline Pan-PRD & $\$ 4.83$ & $-16.2 \%$ \\
\hline Inland & $\$ 4.89$ & $-15.2 \%$ \\
\hline Vietnam & $\$ 5.58$ & $-3.2 \%$ \\
\hline India & $\$ 5.31$ & $-7.9 \%$ \\
\hline Mexico & $\$ 5.81$ & $0.8 \%$ \\
\hline
\end{tabular}

Table 6 shows the comparison of LC among candidate locations at base scenario. The result suggests relocation to Pan-PRD will achieve highest LC savings of $16.2 \%$. Relocation to Vietnam and India will bring less cost savings in comparison with other candidate locations in China. Lower hourly rates of direct labors in these two countries are offset by higher logistics costs and lower labor productivity. The research assumes $20 \%$ more man hours to be used in Vietnam and India than in China, based on inputs from industrial experts. Relocation to Mexico will increase LC slightly.

\subsection{Sensitivity Analysis}

Figure 1 shows the impact of RMB $¥$ to US\$ exchange rate on LC. If RMB $¥$ to US\$ appreciates $20 \%$ from base scenario rate 0.14 , all three candidate locations in China will lose cost advantage to India. If RMB¥ to US\$ appreciates another $10 \%$ more, Vietnam will become the second best location after India. The result suggests that cost advantage of manufacturing in China is no longer significant and it is vulnerable to RMB appreciation.

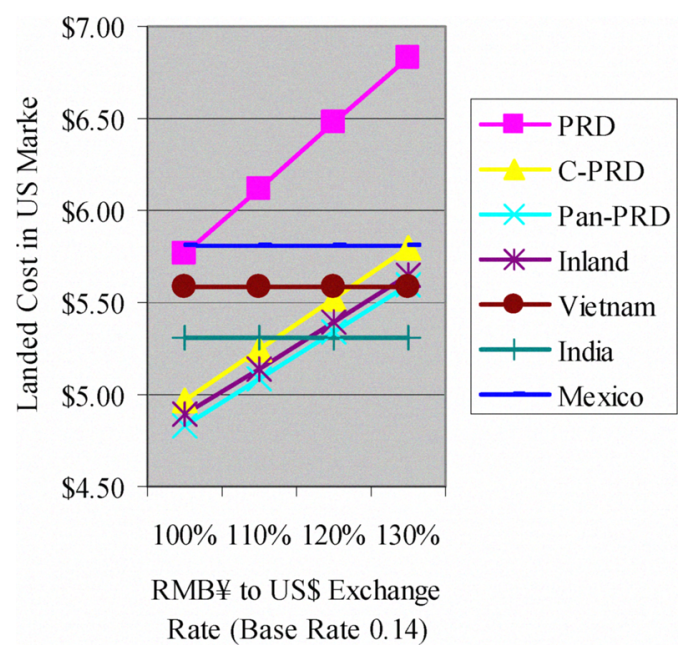

Figure 1: Sensitivity analysis on exchange rate

Labor costs in all countries have the tendency to rise over time. Figure 2 shows the impact of labor cost increase on LC, assuming labor costs in all locations rise at the same pace and other factors do not change. LC for manufacturing in Mexico is most sensitive as its labor cost is the highest among candidate locations. The comparative advantages of manufacturing in Vietnam will increase if labor costs in all locations rise at the same pace, as Vietnam currently has the lowest labor cost. Overall, labor cost increases at the same pace appear to be of less dramatic impact on optimal locations. 


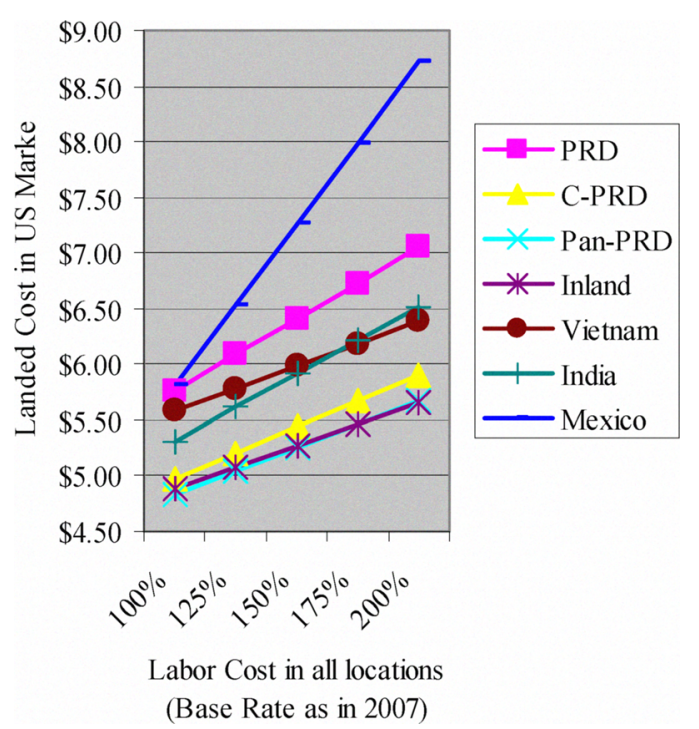

Figure 2: Sensitivity analysis on labor cost

Figure 3 demonstrates the result of sensitivity analysis on oil price. It shows that manufacturing in Mexico would become most competitive to serve US market if oil price exceeds US $\$ 270$ per barrel. In general, low-cost manufacturing in Asia to serve US market is very sensitive to oil price, especially for the locations with very high logistics costs, for example, Inland China, Vietnam and India.

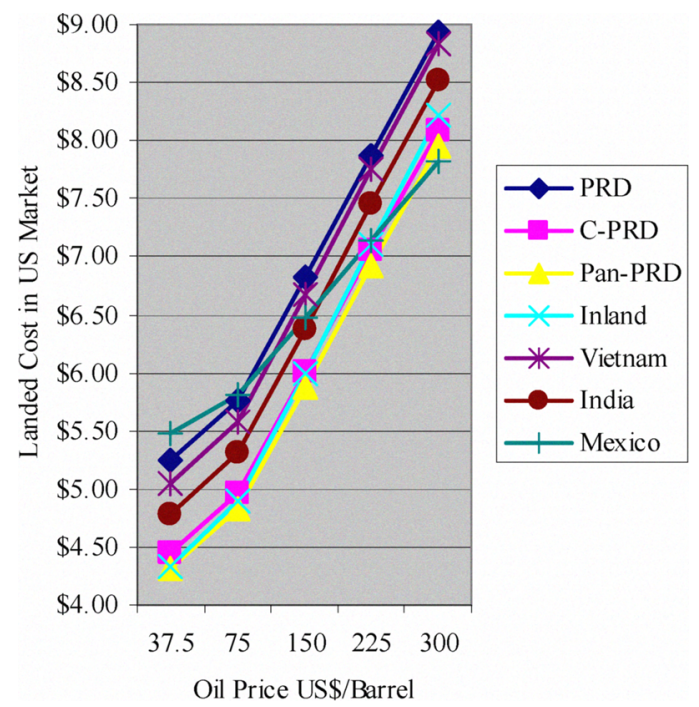

Figure 3: Sensitivity analysis on oil price

Figure 4 shows the comparison of LC when export VAT rebate in China changes. Standard VAT rate in China is $17 \%$. The research assumes net profit after tax to be at $5 \%$ of sales revenues at all candidate locations. If rebate rate changes from base scenario rate $13 \%$ to $0 \%, \mathrm{LC}$ of manufacturing in China would change by about $10 \%$. Such an impact on the cost competitiveness of manufacturing in China is similar as RMB appreciation by $10 \%$. It shows that export rebate rate does have a significant impact on the LC.

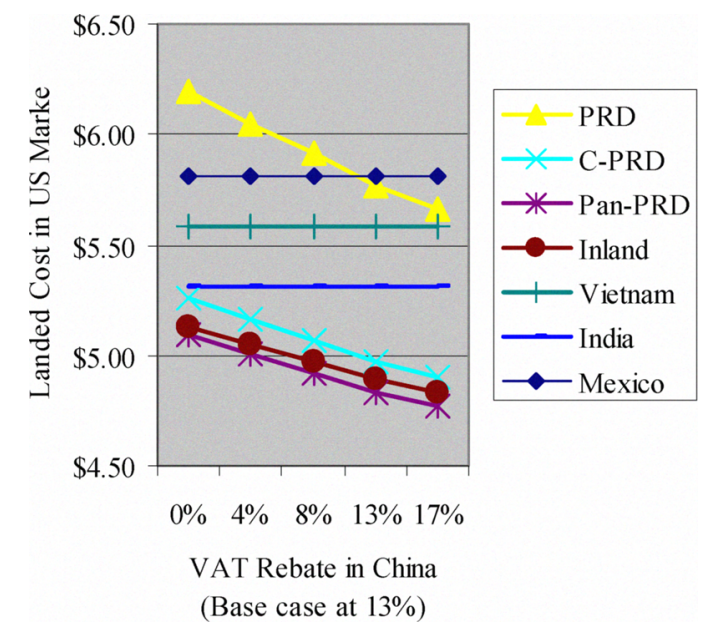

Figure 4: Sensitivity analysis on VAT rebate

\subsection{Optimum Relocation Destination}

Modeling results and analysis confirm that PRD has lost cost competitiveness on low-cost global manufacturing activities in comparison with some other areas of China and nearby Asia low-cost countries. Based on the comparison of $\mathrm{LC}$ at base scenario, relocation to Pan-PRD seems to be the best choice for the hypothetical footwear manufacturer. Besides lowest LC, relocation to Pan-PRD will bring least challenges on supply chain lead time, language, culture difference, or availability of skilled labors. However, the cost advantage of manufacturing in Pan-PRD is subject to changes in business factors. RMB appreciation and export rebate decrease in China would make nearby low-cost countries more favorable. Oil price increase might cause near to market locations more competitive.

\section{MANAGERIAL IMPLICATIONS}

Modeling results offer insights on the relocation decisions of low-cost global manufacturing activities. In terms of labor cost alone, Vietnam and India are more competitive than China and Mexico. Logistics costs in China are lower than many other low-cost countries, due to its relatively more developed infrastructure. Mexico has geographical proximity to serve US market, whose benefit would become more prominent if oil prices stay at very high level. As manufacturing relocation to Pan-PRD is vulnerable to certain changes in business factors, it is advisable for manufacturers to avoid large amount of investment on fixed assets.

The trend of global manufacturing relocation out of PRD brings implications on global supply chain 
dynamics. Since the cost advantage of manufacturing in China has become slim and vulnerable, some manufacturing activities are likely to move to alternative low-cost countries like Vietnam and India. As a consequence, global supply chain lead time of affected products will increase by two days to two to three weeks. The potential impact of oil price increase might be most dramatic, to cause low-cost global manufacturing relocating to near to major markets. Sourcing and purchasing functions and their associated quality control activities may need to follow manufacturers to relocate.

The global manufacturing trend is expected to have fundamental impact on the economy of certain regions. PRD will need to develop some other industries to fill up the economy "vacuum" when many manufacturers move out. Hong Kong has already started to feel the pain as its ports depend very much on cargo from PRD. Recipient locations will observe an inflow of investment and rapid growth of the regional economy. As the PRD manufacturing base is of very large scale, receiving even a small portion of its manufacturers may have a significant impact on the regional economy.

\section{CONCLUSIONS}

The research concerns a newly started trend of global manufacturing relocating out of PRD of China, where has been "The World's Factory" since the 1990s. The phenomenon is triggered by dramatic changes in business factors. A MIP model is presented in the paper to evaluate the impact of business factors on global manufacturing relocation decisions. Modeling results suggest that Pan-PRD is the optimum relocation destination at base scenario. However, optimum location may change to Vietnam and India if RMB appreciates and export rebate in China decreases. High oil prices may make Mexico most competitive. The global manufcturing trend is expected to impact supply chain dynamics and regional economy.

The research has its limitations. First, as most products from PRD compete mainly on cost in international markets, the research has a heavy focus on cost. For companies with different competitive strategies like marketing or $R \& D$, results from the research may not be applicable. In addition, real life manufacturing relocation decisions usually involve more business factors than those in the MIP model. Modifications may be required before applying the MIP model in real life industrial cases. Future research opportunities lies in the areas of regional economy, public policy responses, global supply chain dynamics and uncertainties.

\section{REFERENCES}

[1] Arisoy, O., "Integrated decision making in global supply chains and networks", Ph.D. Thesis, University of Pittsburgh, USA, 2007

[2] Beamon, B.M., "Supply chain design and analysis: models and methods", International Journal of Production Economics, Vol.55, No.3, pp281-294, 1998

[3] Bilgen, B., \& I. Ozkarahan, "Strategic tactical and operational production-distribution models: a review", International Journal of Technology Management, Vol.28, No.2, pp151-171, 2004

[4] Fawcett, S.E., L. Birou, \& B.C. Taylor, "Supporting global operations through logistics and purchasing", International Journal of Physical Distribution \& Logistics Management, Vol.23, No.4, pp3-11, 1993

[5] Ferdows, K. "Global manufacturing rationalization: the design and management of international factory networks", In K. Ferdows (Ed.), "Managing International Manufacturing" (pp. 41-65), New York: Elsevier Science Publishers B.V, North-Holland, 1989

[6] Ferdows, K., "Making the most of foreign factories", Harvard Business Review, Vol.75, No.2, pp73-88, 1997

[7] Huchzermeier, A., \& M.A. Cohen, "Valuing operational flexibility under exchange rate risk", Operations Research, Vol.44, No.1, pp100-113, 1996

[8] Meixell, M.J., \& V.B. Gargeya, "Global supply chain design: A literature review and critique", Transportation Research Part E, Vol.41, pp531-550, 2005

[9] Min, H., \& G. Zhou, "Supply chain modeling: past, present and future", Computers \& Industrial Engineering, Vol.43, pp231-249, 2002

[10] Mohamed, Z.M., \& M.A. Youssef, "A production, distribution and investment model for a multinational company", Journal of Manufacturing Technology Management, Vol.15, No.6, pp495 - 510, 2004

[11] Pontrandolfo, P., \& O.G. Okogbaa, "Global manufacturing: a review and a framework for planning in a global corporation", International Journal of Production Research, Vol.37, No.1, pp1-19, 1999

[12] Vidal, C.J., \& M. Goetschalckx, "Strategic production-distribution models: A critical review with emphasis on global supply chain models", European Journal of Operational Research, Vol.98, pp1-18, 1997

[13] Vidal, C.J., \& M. Goetschalckx, "Modeling the effect of uncertainties on global logistics systems", Journal of Business Logistics, Vol.21, No.1, pp95-120, 2000 